\title{
Comparison of Cloud Base Height Derived from a Ground-Based Infrared Cloud Measurement and Two Ceilometers
}

\author{
Lei Liu, Xue-jin Sun, Xi-chuan Liu, Tai-chang Gao, and Shi-jun Zhao \\ College of Meteorology and Oceanography, PLA University of Science and Technology, Nanjing 211101, China \\ Correspondence should be addressed to Lei Liu; liuleidll@gmail.com
}

Received 13 September 2014; Revised 1 January 2015; Accepted 1 January 2015

Academic Editor: Hiroyuki Hashiguchi

Copyright (C) 2015 Lei Liu et al. This is an open access article distributed under the Creative Commons Attribution License, which permits unrestricted use, distribution, and reproduction in any medium, provided the original work is properly cited.

The cloud base height $(\mathrm{CBH})$ derived from the whole-sky infrared cloud-measuring system (WSIRCMS) and two ceilometers (Vaisala CL31 and CL51) from November 1, 2011, to June 12, 2012, at the Chinese Meteorological Administration (CMA) Beijing Observatory Station are analysed. Significant differences can be found by comparing the measurements of different instruments. More exactly, the cloud occurrence retrieved from CL31 is 3.8\% higher than that from CL51, while WSIRCMS data shows $3.6 \%$ higher than ceilometers. More than $75.5 \%$ of the two ceilometers' differences are within $\pm 200 \mathrm{~m}$ and about $89.5 \%$ within $\pm 500 \mathrm{~m}$, while only $30.7 \%$ of the differences between WSIRCMS and ceilometers are within $\pm 500 \mathrm{~m}$ and about $55.2 \%$ within $\pm 1000 \mathrm{~m}$. These differences may be caused by the measurement principles and $\mathrm{CBH}$ retrieval algorithm. A combination of a laser ceilometer and an infrared cloud instrument is recommended to improve the capability for determining cloud occurrence and retrieving CBHs.

\section{Introduction}

Cloud plays an important role in the global radiation budget and the hydrological cycle. Macroscopic properties of cloud, such as cloud types, cloud base heights, and temporal and spatial distributions of cloudiness, are important characteristics for describing the impact of clouds in a changing climate [1]. Historically, these cloud properties have been recorded by human observers for over 100 years. With the progress of the automated meteorological measurement technology, many instruments such as the ceilometer [2], whole-sky imager (WSI) [3], total-sky imager (TSI) [4], allsky imager (ASI) [5], infrared cloud imager (ICI) [6], wholesky infrared cloud-measuring system (WSIRCMS) [7], and all sky infrared visible analyzer (ASIVA) [8] have been developed and improved to obtain these cloud properties. Many investigations [9-11] have been performed to know the differences in cloud characteristics introduced by instruments and human observers.

Two types of instruments should be mentioned in order to make the transition from a human observer to the instruments. One is the infrared camera system and the other is the ceilometer. Infrared cameras are considered to be the potential system to provide cloud cover, cloud base height
$(\mathrm{CBH})$, and cloud type with stable performance from day to night $[6,7,12,13]$. Ceilometers are the most common instruments devoted to determining the cloud base height. The WMO recognizes that laser ceilometer is the most accurate, reliable, and efficient tools for measuring $\mathrm{CBH}$ from the ground compared with other equipment $[14,15]$. However, previous study [13] shows that the differences between CBHs derived from infrared cloud imagers and from ceilometers can be explained by the different measurement principles, the different definition of $\mathrm{CBH}$, and the measurement errors from both the instruments.

It is known that for the passive infrared sensing technology of $\mathrm{CBH}$, clouds are assumed to be blackbody layers, so the monotonic relationship between $\mathrm{CBH}$ and downwelling infrared radiance can be used to calculate $\mathrm{CBH}$ [13]. However, since many clouds should not be treated as blackbody, the monotonic relationship assumption will make an over estimation of the $\mathrm{CBHs}$ derived by infrared cloud imagers compared with the actuals. Ceilometers usually use a laser or other light source to determine the height of a cloud base; therefore, $\mathrm{CBH}$ can easily be derived from the strongest section of the signal returned by the ceilometer [16]. But the highest backscatter signal is not always from the base of the cloud. What is more, the reduction of laser energy caused 
by aerosols below cloud layers leads to low detectability of $\mathrm{CBH}$. Since both the infrared cloud imagers and the ceilometers have their own advantages and disadvantages of $\mathrm{CBH}$ measurement, it is necessary to investigate and find the limitations of each instrument.

In this paper, the differences of $\mathrm{CBHs}$ derived from a WSIRCMS and two ceilometers under specific cloud types and weather conditions are analysed. The source of these differences is determined. The data sets and techniques to retrieve $\mathrm{CBH}$ of the lowest cloud from different instruments are described in Section 2. CBHs retrieved from passive remote sensor and two active remote sensors are compared and analysed in Section 3. A summary and conclusions are provided in Section 4.

\section{Data and CBH Retrieval Methodology}

A series of CBH comparison experiment using WSIRCMS and two ceilometers including Vaisala CL31 and CL51 were performed at the CMA Beijing Observatory Station $(39.56 \mathrm{~N}$, 116.17E, 55 m ASL.) from November 1, 2011, to June 12, 2012.

The WSIRCMS is an IR camera that measures the downwelling atmospheric radiance in the $8-14 \mu \mathrm{m}$ wavelength bands for zenith angles less than $75^{\circ}$ every 15 minutes. Assuming that the cloud radiates like a blackbody, the radiance for a cloud layer at the heights of $2.5,6$, and $11 \mathrm{~km}$, can be calculated separately by SBDART (Santa Barbara DISORT Atmospheric Radiative Transfer) program [17] with a known atmospheric conditions. CBHs of different infrared radiations measured by WSIRCMS can be calculated by interpolation [13].

Two ceilometers (Vaisala CL31 and CL51) are in continuous operation. Both of the ceilometers use InGasAs diode emitting at the $910 \mathrm{~nm}$ wavelength. The reflection of light backscatter caused by haze, fog, mist, precipitation, and clouds is measured by the laser pulses traversing the sky [18]. The resulting backscatter profile, that is, the signal strength versus the height, is stored and processed, and the $\mathrm{CBHs}$ are detected by the algorithm provided by Vaisala. The cloud base height reports up to $7500 \mathrm{~m}$ for CL31. The CL51 ceilometer has a more powerful laser source and smaller beam divergence to enable cloud base reports up to $13000 \mathrm{~m}$. The ceilometers report the cloud base with a vertical resolution of $5 \mathrm{~m}$ (CL31) and $10 \mathrm{~m}$ (CL51) every 6-120 s.

\section{Comparison of CBH Retrieved from Different Instruments}

In this section, the CBHs retrieved from passive remote sensor and two active remote sensors are compared. Firstly, for comparing the accuracy of the ceilometer retrievals, the $\mathrm{CBHs}$ derived from the two active remote sensors Vaisala CL51 (Vceil51CBH) and CL31 (Vceil31CBH) are presented. Then, the CBHs from WSIRCMS (IRCBH) and ceilometer (VceilCBH) are compared to show the differences between the passive remote sensor and the active remote sensor.

3.1. Vceil31CBH versus Vceil51CBH. The ceilometer CL31 and CL51 used in this study are both zenith pointing measurements, which can detect three cloud layers simultaneously

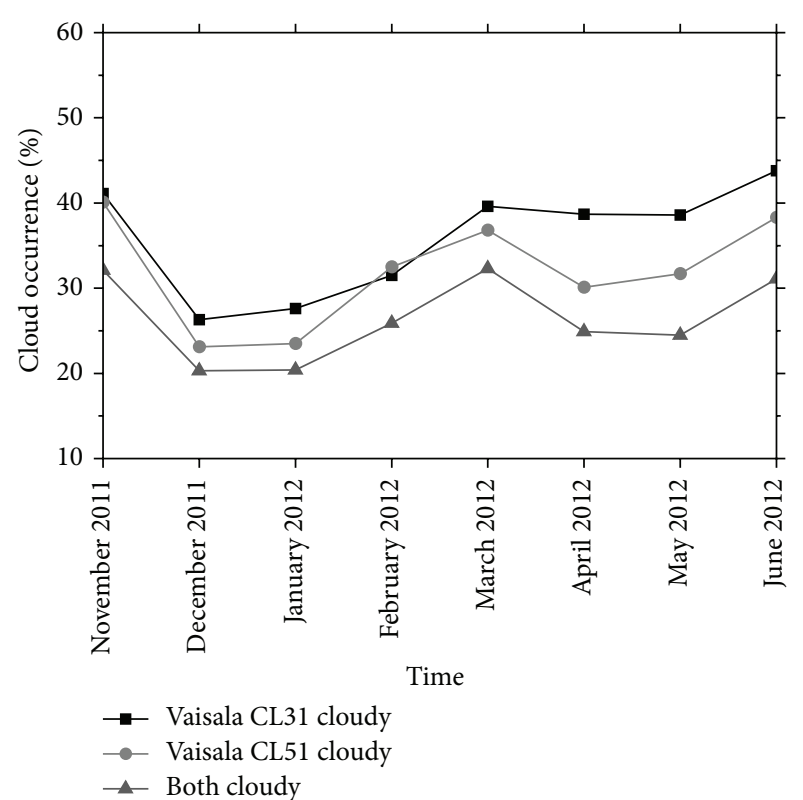

FIGURE 1: Monthly cloud occurrence for the period November 2011 to June 2012, as derived from Vaisala ceilometers CL31 and CL51.

every $1 \mathrm{~min}$. The lowest cloud layer is chosen for comparison. Totally 320,138 data pairs are used for comparison after time matching, with above 40,000 datasets for each month except in June 2012.

3.1.1. Cloud Occurrence. Cloud occurrence is defined as the ratio between the numbers of registers with detected clouds with respect to the total available records [15]. The numbers of cloudy-sky periods identified by each ceilometer and simultaneously by both instruments are computed for comparison (Figure 1).

It is shown that the cloud occurrence retrieved from ceilometer CL31 is higher than that from ceilometer CL51 for almost every month except February 2012; meanwhile, the average cloud occurrence of CL31 shows 3.8\% higher than CL51. The maximum difference (8.6\%) appears in April 2012. It should be noted that the distance between two ceilometers is only $20 \mathrm{~m}$; besides, the ceilometer CL51 is a recently developed instrument which means more sensitively than the detection using CL31 instruments [19].

Further analysis shows that in the case of fog and haze, the ceilometer CL31 is likely to give a doubtful cloud layer observation at about $1000 \mathrm{~m}-1500 \mathrm{~m}$ in height. This inevitably leads to an increasing amount of detections of the cloud layers with the $\mathrm{CBH}$ between $1000 \mathrm{~m}$ and $1500 \mathrm{~m}$ reported by CL31. We think this issue is caused by the imperfect CBH retrieval algorithm of CL31. An example case with the vertical profiles of the attenuated backscatter from CL51 and CL31 instruments is shown in Figure 2. It seems that the $\mathrm{CBH}$ retrieval algorithm of CL51 has been improved to reduce the incorrect assessment, as further described in Section 3.1.2. In addition, although the CL51 instructions indicate that it is possible to detect the cloud ranging up to $13,000 \mathrm{~m}$, there are only 326 datasets for $\mathrm{CBH}$ greater than $8,000 \mathrm{~m}$ in the 


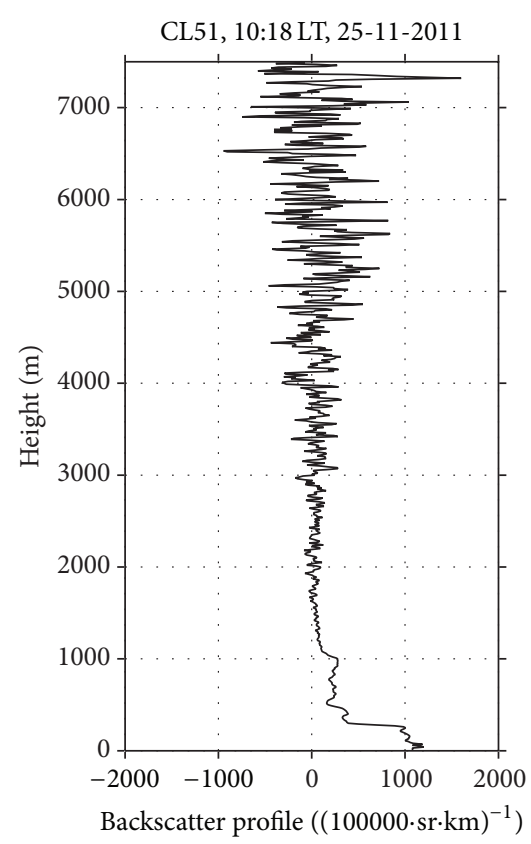

(a)

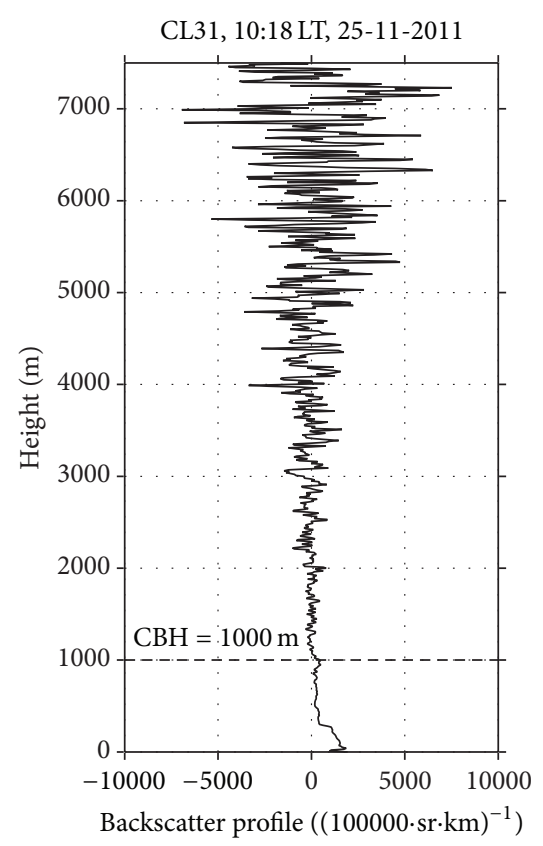

(b)

FiguRE 2: Vertical profiles of the attenuated backscatter coefficient from both ceilometers (25 November 2011): (a) Vaisala CL51 and (b) Vaisala CL31.

actual measurement, accounting for $3.9 \%$ of the total highlevel cloud (8420). It can be considered that in the urban region where haze often occurs, the detectability of cloud by ceilometers like CL31 and CL51 is very low for CBH above $8,000 \mathrm{~m}$.

3.1.2. CBH Distributions. The CBH differences between ceilometers CL31 and CL51 for the whole dataset can be observed in the scatterplot of Figure 3(a). The result shows good consistency except for the cases of Vceil31CBH around $1,000 \mathrm{~m}$ in which the corresponding Vceil51CBH are higher. From the frequency distribution of the $\mathrm{CBH}$ differences shown in Figure 3(b), it can be found the deviations are nearly symmetrically distributed around zero. The mean difference (overall bias) is merely $-110 \mathrm{~m}$, more than $75.5 \%$ of the differences are within $\pm 200 \mathrm{~m}$, and about $89.5 \%$ of the differences are within $\pm 500 \mathrm{~m}$.

Figures 3(c) and 3(d) show the frequency distributions of $\mathrm{CBH}$ retrieved with ceilometers for the whole analysed period. The histogram for all $\mathrm{CBH}$ together has the maximum for the bin cantered at $500 \mathrm{~m}-1,500 \mathrm{~m}$ and shows a progressive decreasing frequency up to the maximum level of detection of the ceilometer. Low-level clouds (below 2,500 m) represent 56.9\% (Vceil31CBH) and 54.4\% (Vceil51CBH) of detected $\mathrm{CBH}$, respectively, midlevel clouds $(2,500 \mathrm{~m}-$ $6,000 \mathrm{~m}$ ) are the $33.1 \%$ and $35.4 \%$, and high-level clouds $(>6,000 \mathrm{~m})$ are the $10.0 \%$ and $10.1 \%$. It is clear that the cloud layers detected by ceilometer CL31 are 2,000 times more than ceilometer CL51 in the range of $500 \mathrm{~m}$ to $1,000 \mathrm{~m}$ and about 4,000 times more in the range of $1,000 \mathrm{~m}$ to $1,500 \mathrm{~m}$. Vertical profiles of the attenuated backscatter coefficient from both ceilometers were further studied. It is shown that, due to the higher laser power and receiver efficiency, the attenuated backscatter coefficient caused by a cloud layer can be detected easily by CL51, of which the 13 February 2012 case in Figure 4 is a typical example. However, the cloud peaks were not shown in the CL31's return. The cloud occurred at the height of $1140 \mathrm{~m}$ reported by CL31 did not exist actually. The built-in software of CL31 may not detect the CBH properly in some cases.

3.2. IRCBH versus VceilCBH. The WSIRCMS can provide $\mathrm{CBH}$ for an elevation angle greater than $15^{\circ}$ every $15 \mathrm{~min}$. For comparison, we choose the lowest height for zenith angles less than $5^{\circ}$ as the CBH detected by WSIRCMS at zenith. The samples with the differences of ceilometers CL31 and CL51 less than $20 \%$ are chosen as the true $\mathrm{CBH}$ values. After time matching, total 21,112 sets of data are retained for analysing.

3.2.1. Cloud Occurrence. The differences for cloud occurrence between WSIRCMS and ceilometers are given in Figure 5. It is shown that the cloud occurrence retrieved from WSIRCMS is higher than that from ceilometers for every month, with the mean difference around $3.6 \%$. The maximum difference appears in the May 2012 with the value $8.2 \%$. In fact, the differences of cloud occurrence in both April and May 2012 seem to be higher than other months which are similar to that between the two ceilometers in Figure 1. The WSIRCMS is a passive instrument with wide angular range. It can record cloud occurrence even if the sky is partially cloudy. But the ceilometers are single point measurements and only when the cloud is present overhead it records cloud occurrence. 


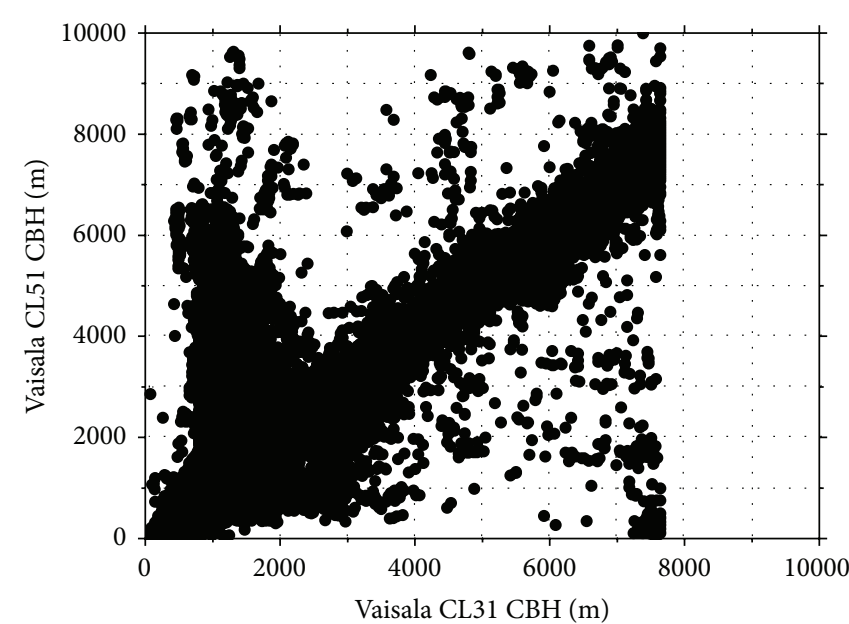

(a)

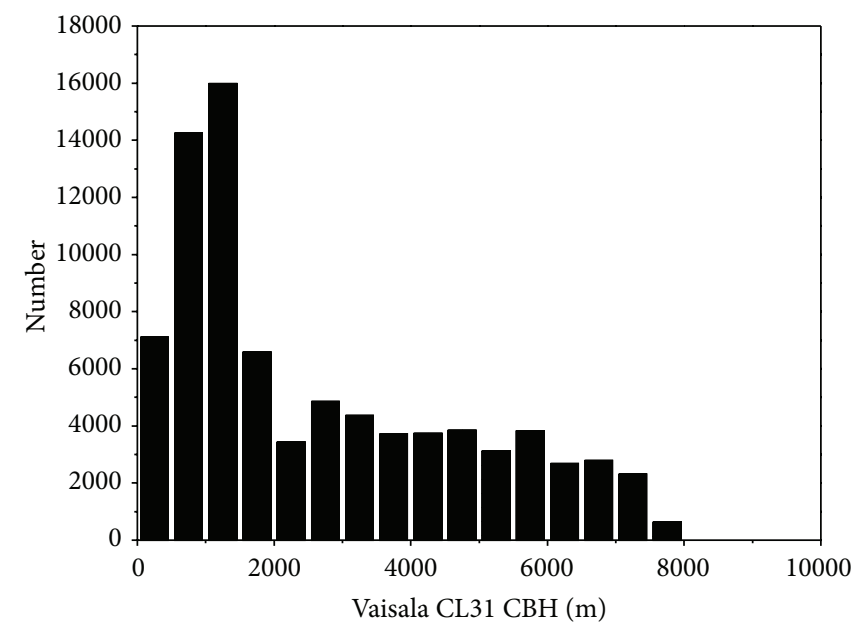

(c)

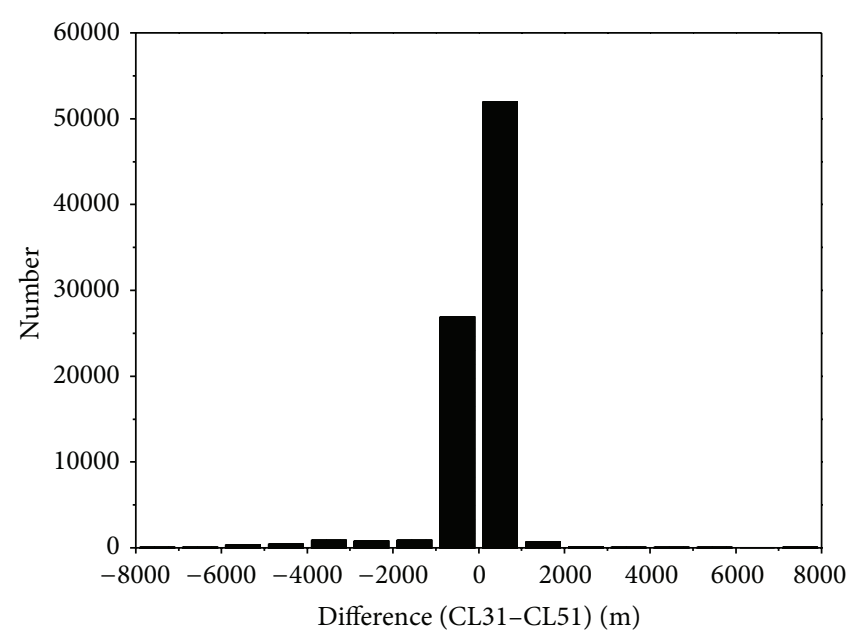

(b)

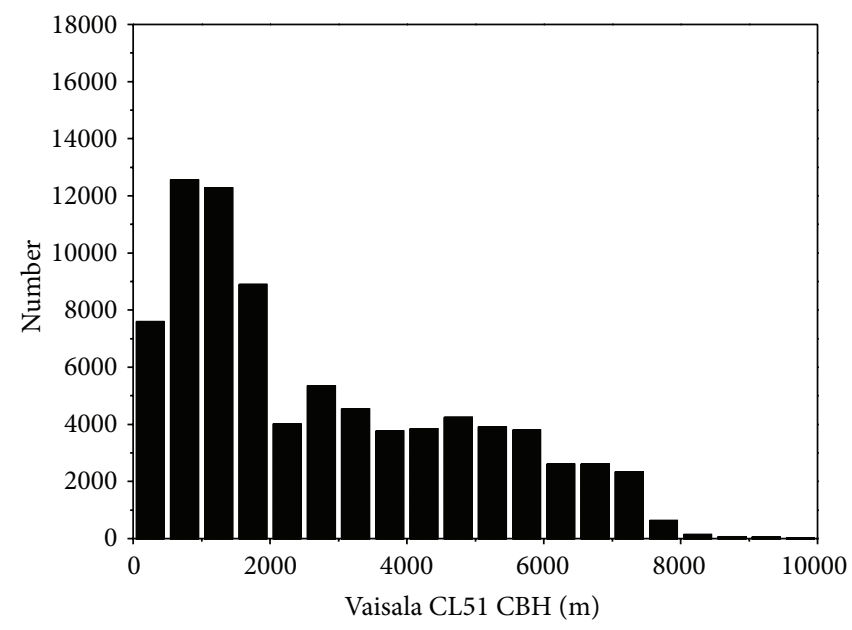

(d)

Figure 3: Cloud base height differences between ceilometers CL31 and CL51 during the period November 1, 2011, and June 12, 2012, at the CMA Beijing Observatory Station.

The averaging time is an important factor, as a longer averaging time will smooth out the peaks of the ceilometer and increases the probability that a vertical time slice through a moving cloud field will represent the actual whole sky situation [10]. Besides, the aerosol layer below clouds will bring out strong attenuation of laser energy, which makes it difficult for detecting clouds with ceilometers. Benefiting from the longer wavelength, the WSIRCMS may partially penetrate aerosols better than ceilometers. Three possible reasons above can be used to explain the differences between WSIRCMS and ceilometers.

From a detailed analysis of Figures 1 and 5, it is found that the difference for cloud occurrence detection of WSIRCMS, CL31, and CL51 is not particularly large. The ceilometers are prone to mistake haze as cloudy-sky; moreover, the ability for detecting high clouds is limited. Although there are much more numbers of high clouds detected by WSIRCMS, it contains some incorrect assessments due to the inaccurate estimation of PWV. Since the two cloud-measuring techniques have respective advantages and disadvantages, it is recommended to complement one another based on the local conditions.

3.2.2. CBH Distributions. Figure 6(a) shows the CBH differences between WSIRCMS and active ceilometers. Compared with Figure 3, it seems that there is a big difference between these two $\mathrm{CBH}$ measuring methods. The frequency distribution of the $\mathrm{CBH}$ differences is shown in Figure 6(b). Only $30.7 \%$ of the differences are within $\pm 500 \mathrm{~m}$, and about $55.2 \%$ of the differences are within $\pm 1000 \mathrm{~m}$. Combined with Figures 6(c) and 6(d), it is shown that the CBHs from WSIRCMS are generally higher than those from ceilometers. The maximum number of occurrences of the CBHs appears in 1,500 m$2,500 \mathrm{~m}$ for WSIRCMS and $500 \mathrm{~m}-1,500 \mathrm{~m}$ for ceilometer CL51. Low-level clouds represent 47.3\% (IRCBH) and 53.5\% (VceilCBH) of detected $\mathrm{CBH}$, respectively, midlevel clouds are the $38.6 \%$ and $37.1 \%$, and high-level clouds are the $9.4 \%$ and $14.1 \%$.

Obviously, the main reason for these differences exists in the $\mathrm{CBH}$ retrieval algorithm for passive infrared cloud 


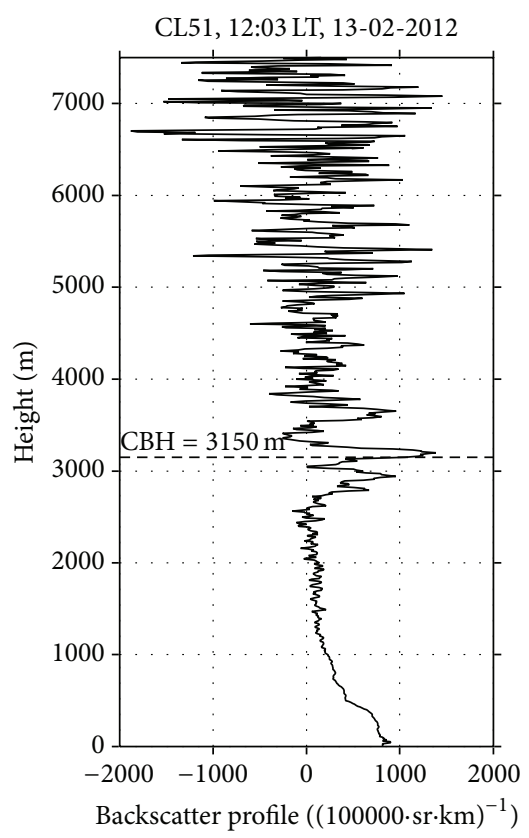

(a)

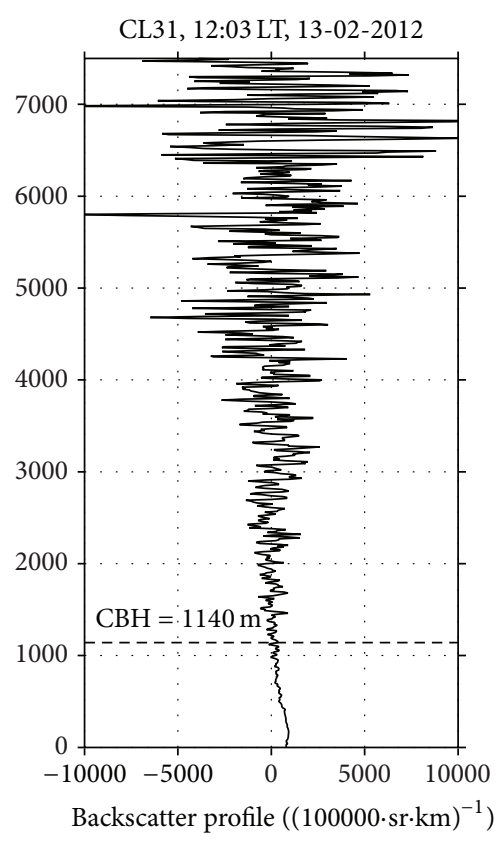

(b)

FIGURE 4: Vertical profiles of the attenuated backscatter coefficient from both ceilometers (13 February 2012): (a) Vaisala CL51 and (b) Vaisala CL31.

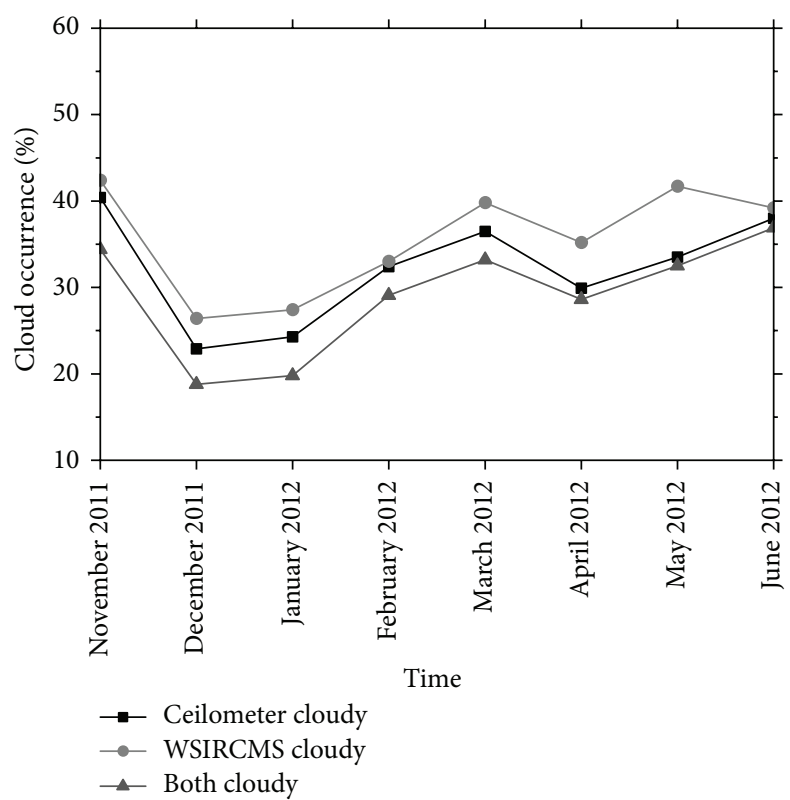

FIGURE 5: Monthly cloud occurrence for the period November 2011 to June 2012, as derived from ceilometer and WSIRCMS.

remote sensing. Clouds are treated as blackbody when the $\mathrm{CBH}$ derived from downwelling infrared radiance. Since this retrieved $\mathrm{CBH}$ is not the real height of the cloud base (equivalent cloud base height), the blackbody assumption is not always valid especially for midlevel and high-level clouds. This is the reason why the accuracy of retrieved CBHs for lowlevel clouds is high but for midlevel and high-level clouds is poor. In general, the $\mathrm{CBH}$ derived from infrared radiance will be higher than the actual cloud base height. For explanation, we chose data of the CBH obtained by ceilometer CL51 and WSIRCMS on 6 January 2012 shown in Figure 7. For this case, the cloud is not very thick and the CBHs from WSIRCMS are higher than that from the ceilometer.

The inaccurate estimated PWV is another reason for the error of $\mathrm{CBH}$ derived from infrared radiance. Since water vapor is the most important factor that affects the downwelling atmospheric radiance in the $8-14 \mu \mathrm{m}$ wavelength bands, the $\mathrm{CBH}$ will be higher for the overvalued PWV and lower for the underestimated PWV, as shown in Figure 8. Figure 9 shows the corresponding PWV values obtained by GPS/MET [20] and estimated from surface temperature and humidity [13]. In this case, the PWV is underestimated, and the $\mathrm{CBH}$ derived from WSIRCMS is lower than that from the ceilometer. Since it is difficult to determine the emissivity of a real cloud and the PWV as well as the atmospheric profile cannot be obtained accurately, the error of $\mathrm{CBH}$ derived from infrared radiance is the result of the combined effects of these factors.

\section{Conclusions}

Comparison of the $\mathrm{CBH}$ outputs from the infrared cloud instrument WSIRCMS and two ceilometers (Vaisala CL31 and CL51) revealed significant differences among these instruments.

In comparisons of the active sensor CL31 and CL51 derived $\mathrm{CBHs}$, the average cloud occurrence retrieved from ceilometer CL31 is $3.8 \%$ higher than that from ceilometer CL51. More than $75.5 \%$ of the differences are within $\pm 200 \mathrm{~m}$ 


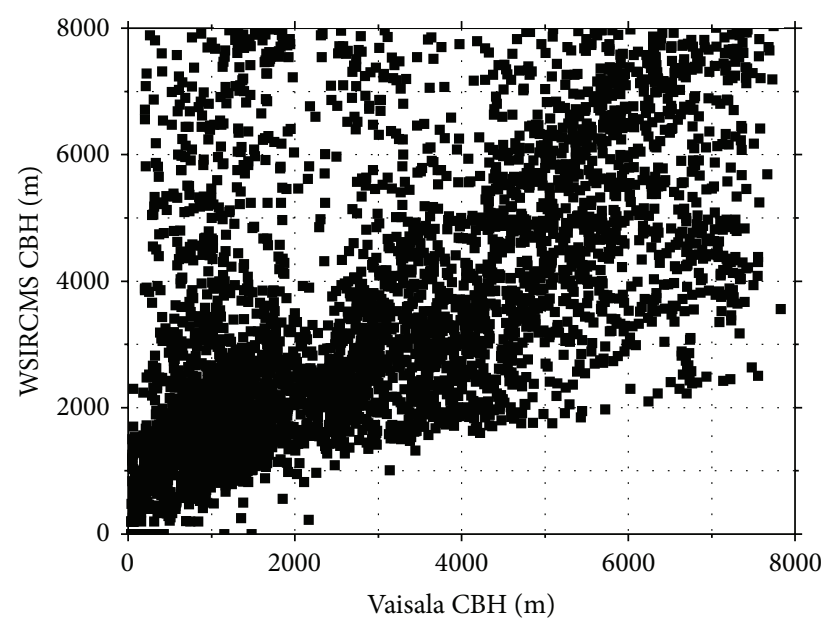

(a)

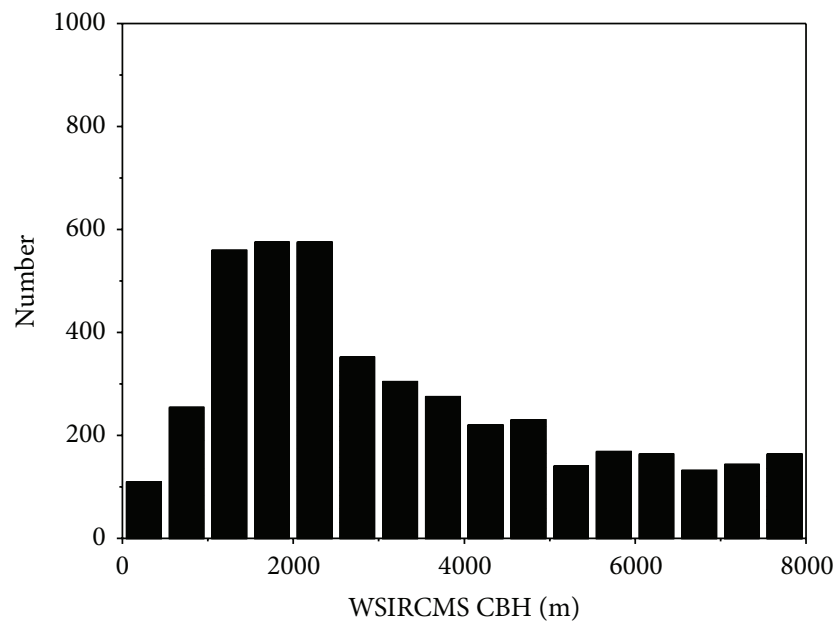

(c)

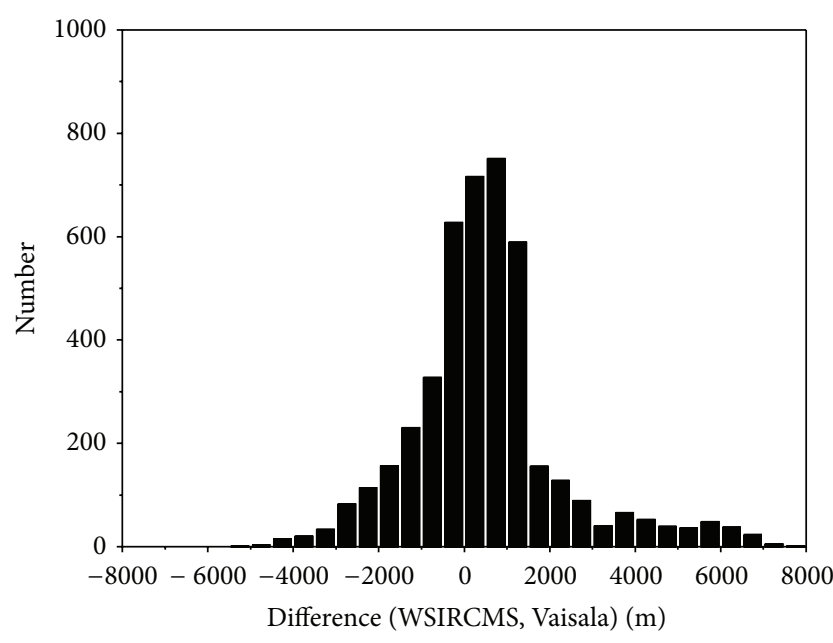

(b)

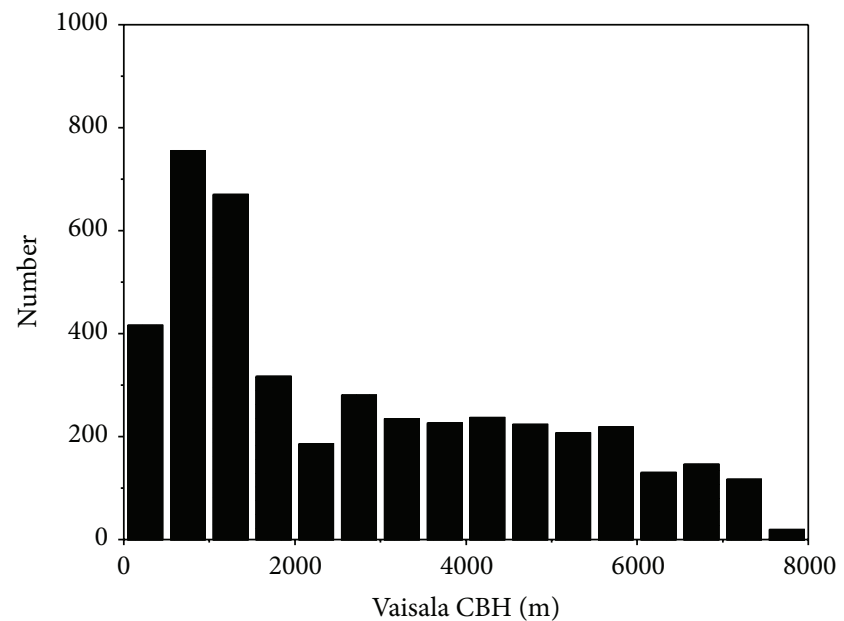

(d)

FIGURE 6: Cloud base height differences between WSIRCMS and ceilometer CL51 during the period November 1, 2011, to June 12, 2012, at the CMA Beijing Observatory Station.

and about $89.5 \%$ of the differences are within $\pm 500 \mathrm{~m}$. It shows a good consistency except for specific cases in which the Vceil31CBH are around 1,000 $\mathrm{m}$ while the corresponding Vceil51CBH are higher. Further analysis shows that in the case of fog and haze, the ceilometer CL31 is likely to give a doubtful cloud layer observation at about $1000 \mathrm{~m}-1500 \mathrm{~m}$ in height. This inevitably leads to an increasing amount of detections of the cloud layers with the CBH between $1000 \mathrm{~m}$ and $1500 \mathrm{~m}$ reported by CL31. In addition, although the CL51 instructions indicate that it is possible to detect the cloud ranging up to $13,000 \mathrm{~m}$, only $3.9 \%$ for $\mathrm{CBH}$ above $8,000 \mathrm{~m}$ of the total highlevel cloud are detected for actual measurement. It can be considered that in the urban region where haze often occurs, the detectability of cloud by ceilometers like CL31 and CL51 is very low for CBH above $8,000 \mathrm{~m}$.

In terms of the active sensor (Vaisala ceilometer-derived) and passive sensor-derived (WSIRCMS-derived) $\mathrm{CBHs}$, it is found the cloud occurrence retrieved from WSIRCMS is higher than that from ceilometers with the mean difference

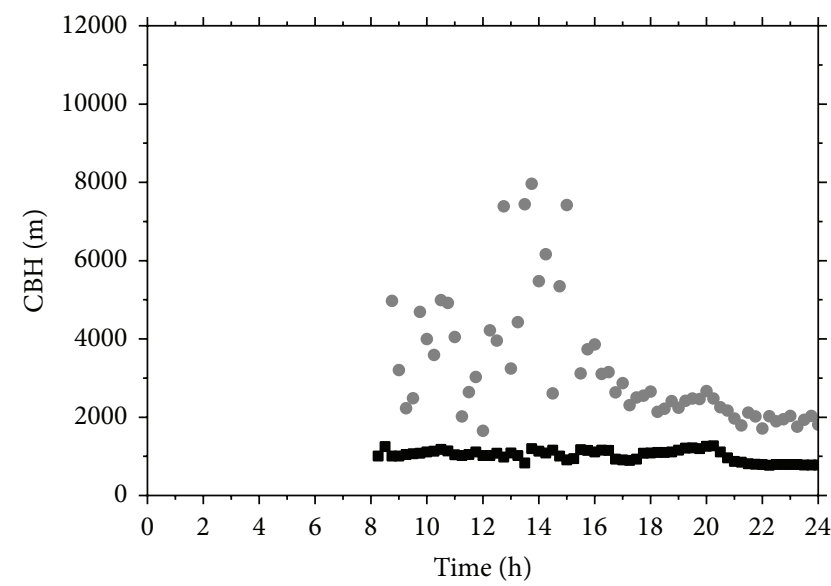

- Vaisala

- WSIRCMS

FIGURE 7: The 6 January 2012 case: CBH values as determined by WSIRCMS (grey circle) and Vaisala CL51 (black square). 


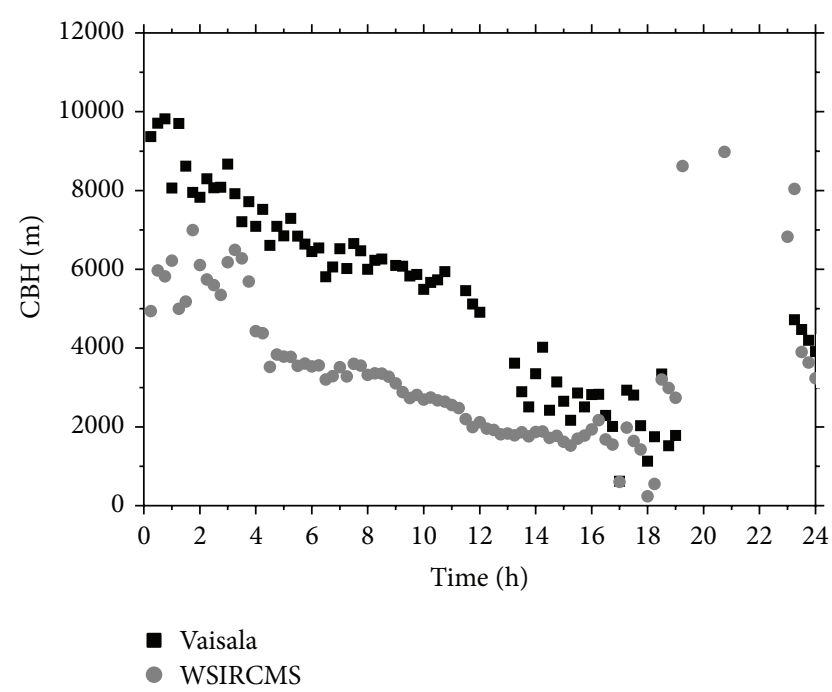

Figure 8: The 16 November 2011 case: $\mathrm{CBH}$ values as determined by WSIRCMS (grey circle) and Vaisala CL51 (black square).

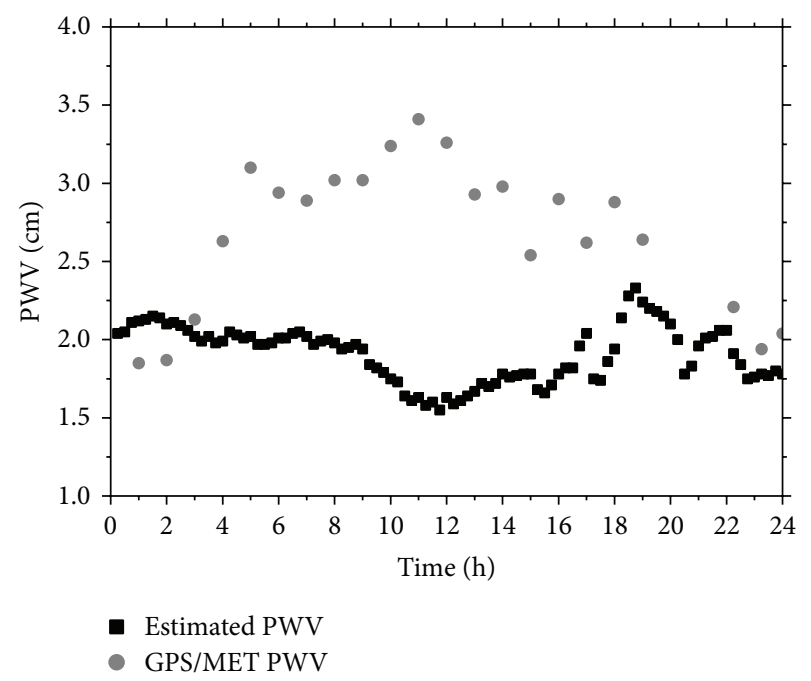

FIGURE 9: The 16 November 2011 case: PWV values as determined by GPS/MET (grey circle) and estimated from surface temperature and humidity (black square).

about 3.6\%. Although there are much more numbers of high clouds detected by WSIRCMS, some incorrect assessments may be involved due to the inaccurate estimation of PWV. CBHs from WSIRCMS are generally higher than those from ceilometers. Only $30.7 \%$ of the differences are within $\pm 500 \mathrm{~m}$ and about $55.2 \%$ of the differences are within $\pm 1000 \mathrm{~m}$. The blackbody assumption and the inaccurate estimated PWV are the possible reasons that can be used to explain the differences.

From the above comparisons, it is highly recommended to develop a combination system containing a laser ceilometer such as the Vaisala CL51 (or comparable) and an infrared cloud instrument such as the WSIRCMS to improve the capability for cloud occurrence and $\mathrm{CBH}$ retrieving. The combination system will be discussed further.

\section{Conflict of Interests}

The authors declare that there is no conflict of interests regarding the publication of this paper.

\section{Acknowledgments}

This research was jointly supported by the National Natural Science Foundation of China (Grants 41205125 and 41305137) and the public benefit sector of China [Grant GYHY (QX) 201306068]. The authors thank the staff and data providers at the Chinese Meteorological Administration (CMA) Beijing Observatory Station for their assistance. They also acknowledge the CMA Meteorological Observation Centre for their support to improve the measurements of cloud parameters. The authors would like to express their gratitude to reviewers for the valuable suggestions that allowed improvement of the paper.

\section{References}

[1] M. D. Zelinka and D. L. Hartmann, "Why is longwave cloud feedback positive?" Journal of Geophysical Research D: Atmospheres, vol. 115, no. 16, Article ID D16117, 2010.

[2] J. L. Gaumet, J. C. Heinrich, M. Cluzeau, P. Pierrard, and J. Prieur, "Cloud-base height measurements with a singlepulse erbium-glass laser ceilometer," Journal of Atmospheric and Oceanic Technology, vol. 15, no. 1, pp. 37-45, 1998.

[3] J. E. Shields, M. E. Karr, R. W. Johnson, and A. R. Burden, "Day/night whole sky imagers for 24-h cloud and sky assessment: history and overview," Applied Optics, vol. 52, no. 8, pp. 1605-1616, 2013.

[4] C. N. Long, J. M. Sabburg, J. Calbó, and D. Pagès, "Retrieving cloud characteristics from ground-based daytime color all-sky images," Journal of Atmospheric and Oceanic Technology, vol. 23, no. 5, pp. 633-652, 2006.

[5] A. Cazorla, F. J. Olmo, and L. Alados-Arbotedas, "Development of a sky imager for cloud cover assessment," Journal of the Optical Society of America A, vol. 25, no. 1, pp. 29-39, 2008.

[6] J. A. Shaw and P. W. Nugent, "Physics principles in radiometric infrared imaging of clouds in the atmosphere," European Journal of Physics, vol. 34, no. 6, pp. S111-S121, 2013.

[7] X. J. Sun, T. C. Gao, D. L. Zhai, S. J. Zhao, and J. G. Lian, "Whole sky infrared cloud measuring system based on the uncooled infrared focal plane array," Infrared and Laser Engineering, vol. 37, no. 5, pp. 761-764, 2008.

[8] D. I. Klebe, R. D. Blatherwick, and V. R. Morris, "Groundbased all-sky mid-infrared and visible imagery for purposes of characterizing cloud properties," Atmospheric Measurement Techniques, vol. 7, no. 2, pp. 637-645, 2014.

[9] N. H. Schade, A. MacKe, H. Sandmann, and C. Stick, "Total and partial cloud amount detection during summer 2005 at Westerland (Sylt, Germany)," Atmospheric Chemistry and Physics, vol. 9, no. 4, pp. 1143-1150, 2009.

[10] R. Boers, M. J. De Haij, W. M. F. Wauben et al., "Optimized fractional cloudiness determination from five ground-based 
remote sensing techniques," Journal of Geophysical Research D: Atmospheres, vol. 115, no. 24, pp. 1-16, 2010.

[11] U. Feister, H. Möller, T. Sattler, J. Shields, U. Görsdorf, and J. Güldner, "Comparison of macroscopic cloud data from groundbased measurements using VIS/NIR and IR instruments at Lindenberg, Germany," Atmospheric Research, vol. 96, no. 2-3, pp. 395-407, 2010.

[12] S. Smith and R. Toumi, "Measuring cloud cover and brightness temperature with a ground-based thermal infrared camera," Journal of Applied Meteorology and Climatology, vol. 47, no. 2, pp. 683-693, 2008.

[13] L. Liu, X.-J. Sun, C. G. Tai-Chang, and S.-J. Zhao, "Comparison of cloud properties from ground-based infrared cloud measurement and visual observations," Journal of Atmospheric and Oceanic Technology, vol. 30, no. 6, pp. 1171-1179, 2013.

[14] World Meteorological Organization, Guide of Meteorological Instruments and Methods of Observation, World Meteorological Organization, Lyon, France, 2008.

[15] M. Costa-Surós, J. Calbó, J. A. González, and J. Martin-Vide, "Behavior of cloud base height from ceilometer measurements," Atmospheric Research, vol. 127, no. 6, pp. 64-76, 2013.

[16] W. L. Eberhard, "Cloud signals from Lidar and rotating beam ceilometer compared with pilot ceiling," Journal of Atmospheric and Oceanic Technology, vol. 3, no. 3, pp. 499-512, 1986.

[17] P. Ricchiazzi, S. Yang, C. Gautier, and D. Sowle, "Sbdart: a research and teaching software tool for plane-parallel radiative transfer in the Earth's atmosphere," Bulletin of the American Meteorological Society, vol. 79, no. 10, pp. 2101-2114, 1998.

[18] V. Oyj, Vaisala Ceilometer CL51 User's Guide, 2012.

[19] M. Wiegner, F. Madonna, I. Binietoglou et al., "What is the benefit of ceilometers for aerosol remote sensing? An answer from EARLINET," Atmospheric Measurement Techniques, vol. 7, no. 7, pp. 1979-1997, 2014.

[20] M. Bevis, S. Businger, T. A. Herring, C. Rocken, R. A. Anthes, and R. H. Ware, "GPS meteorology: remote sensing of atmospheric water vapor using the global positioning system," Journal of Geophysical Research: Atmospheres, vol. 97, no. 15, pp. 15787-15801, 1992. 

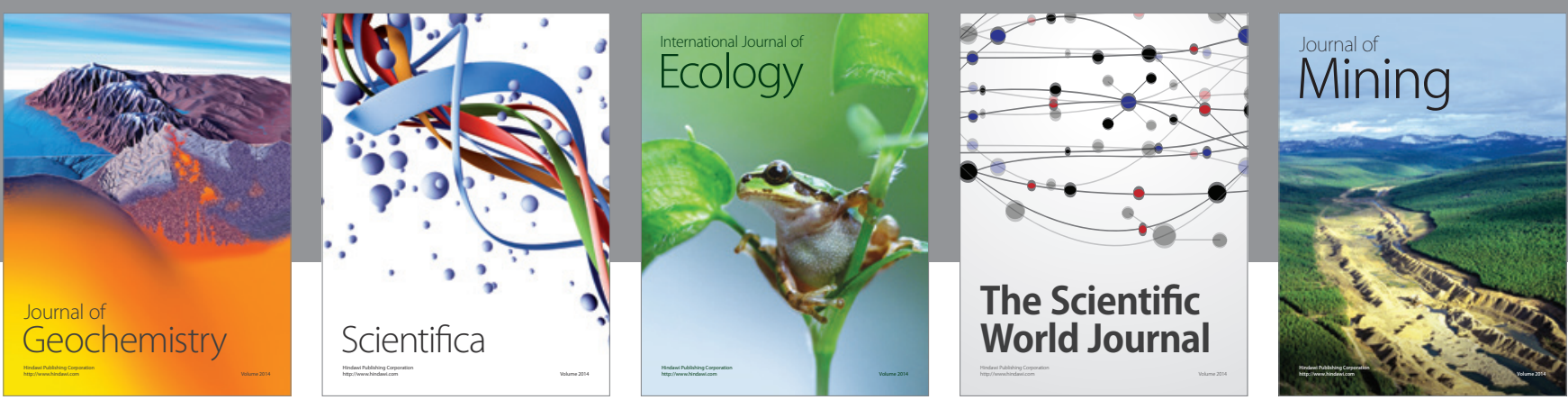

The Scientific World Journal
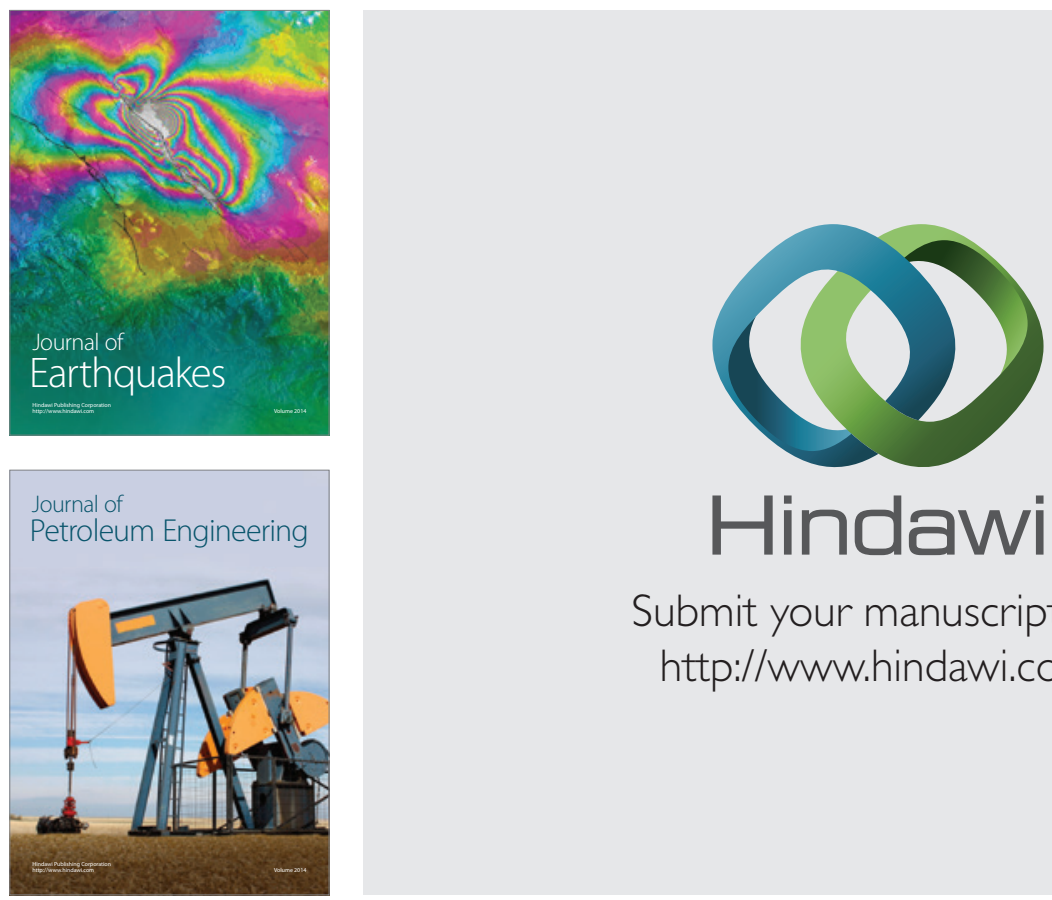

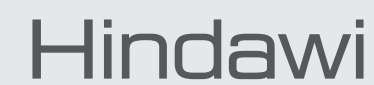

Submit your manuscripts at

http://www.hindawi.com
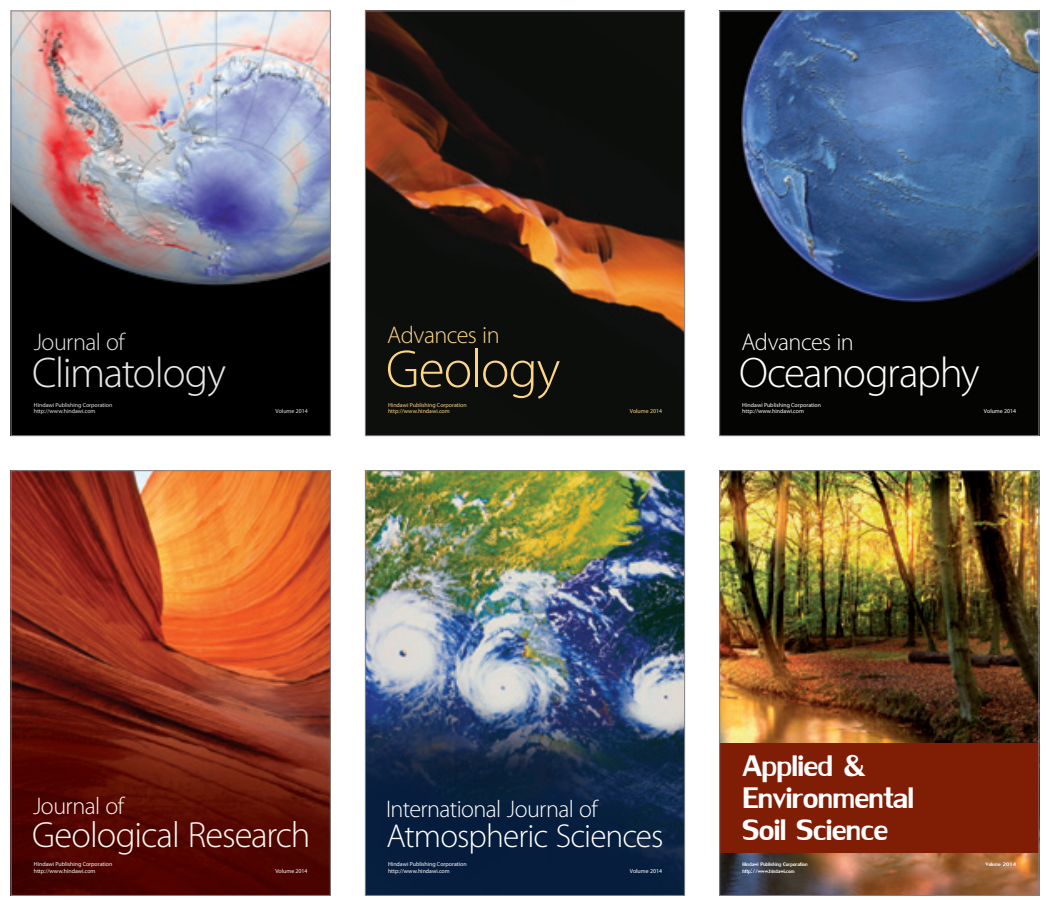
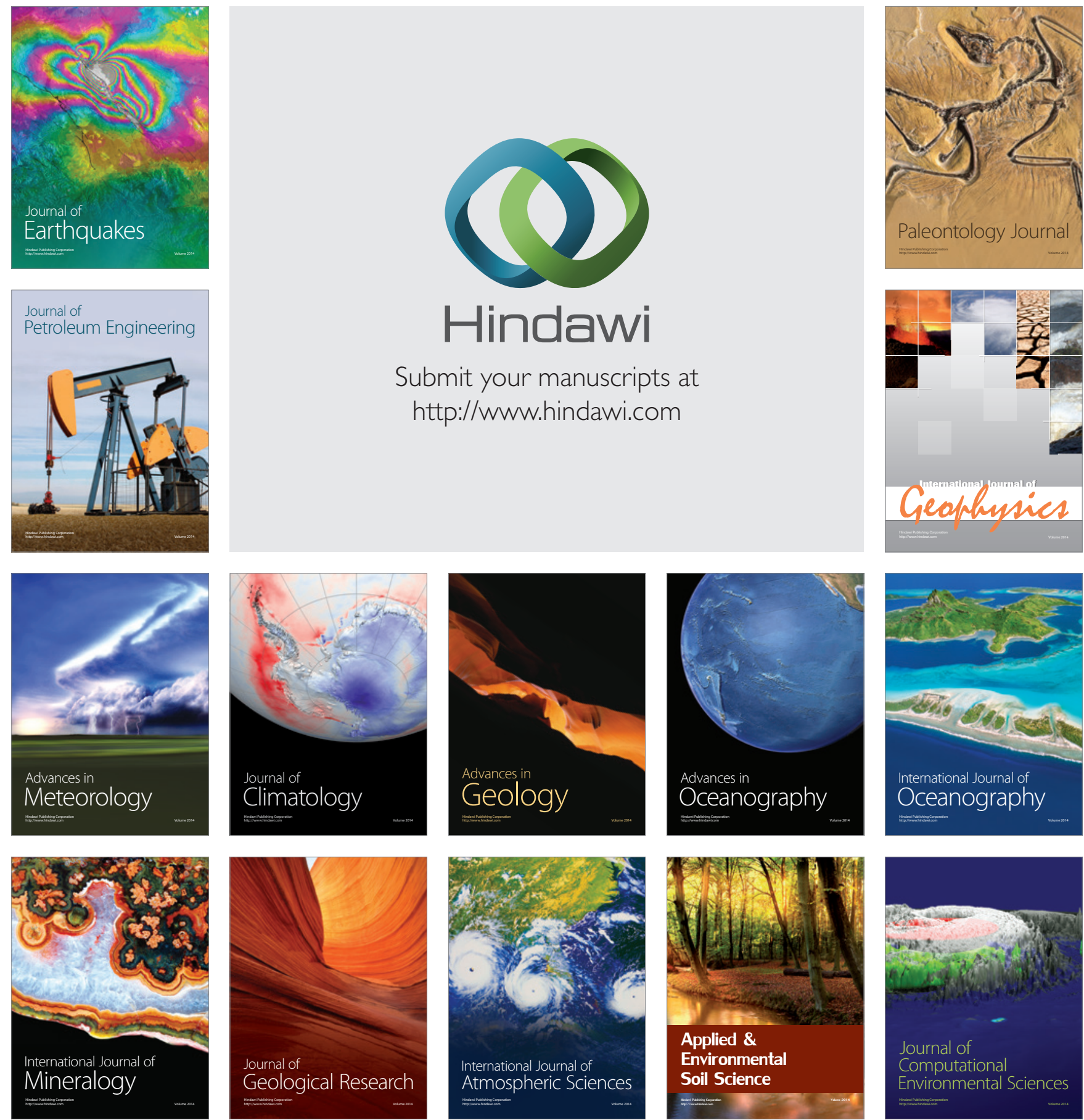